\title{
Interneuron transplantation: a prospective surgical therapy for medically refractory epilepsy
}

\author{
Stephen C. Harward, MD, PhD, ${ }^{1}$ and Derek G. Southwell, MD, PhD ${ }^{1-3}$ \\ Departments of ${ }^{1}$ Neurosurgery and ${ }^{2}$ Neurology; ${ }^{3}$ Graduate Program in Neurobiology; Duke University, Durham, North Carolina
}

Excitatory-inhibitory imbalance is central to epilepsy pathophysiology. Current surgical therapies for epilepsy, such as brain resection, laser ablation, and neurostimulation, target epileptic networks on macroscopic scales, without directly correcting the circuit-level aberrations responsible for seizures. The transplantation of inhibitory cortical interneurons represents a novel neurobiological method for modifying recipient neural circuits in a physiologically corrective manner. Transplanted immature interneurons have been found to disperse in the recipient brain parenchyma, where they develop elaborate structural morphologies, express histochemical markers of mature interneurons, and form functional inhibitory synapses onto recipient neurons. Transplanted interneurons also augment synaptic inhibition and alter recipient neural network synchrony, two physiological processes disrupted in various epilepsies. In rodent models of epilepsy, interneuron transplantation corrects recipient seizure phenotypes and associated behavioral abnormalities. As such, interneuron transplantation may represent a novel neurobiological approach to the surgical treatment of human epilepsy. Here, the authors describe the preclinical basis for applying interneuron transplantation to human epilepsy, discuss its potential clinical applications, and consider the translational hurdles to its development as a surgical therapy.

https://thejns.org/doi/abs/10.3171/2020.2.FOCUS19955

KEYWORDS epilepsy; interneuron transplantation; inhibition; regenerative medicine

$\mathrm{E}$ PILEPSY, a condition affecting approximately $1 \%$ of the population, is refractory to medical therapies in nearly $30 \%$ of cases. ${ }^{8,13}$ Surgical treatments for epilepsy, which include brain resection, laser ablation, and neurostimulation, can be effective treatment adjuncts for medically refractory epilepsy. However, due to limiting factors such as stringent criteria for patient selection, significant postoperative morbidity, and suboptimal seizure outcomes, current surgical modalities remain inadequate for fully treating the diverse forms of medically refractory epilepsy.

Neural excitatory-inhibitory imbalance is central to epilepsy pathophysiology. ${ }^{59}$ Numerous types of epilepsy, such as mesial temporal lobe epilepsy (MTLE), involve molecular and cellular abnormalities that promote neural hyper-excitation and network hyper-synchrony. ${ }^{46,59}$ The dysfunction and loss of inhibitory interneuron populations is one pathogenetic factor in these processes. As such, manipulations that augment inhibitory cellular function could reduce the initiation and propagation of epileptic neural activity.
Over the last 15 years, cortical interneuron precursor transplantation has emerged as a novel technique for adding inhibitory cellular elements to neural circuits. ${ }^{1,67}$ When transplanted from the embryonic brain or from in vitro cell culture preparations, immature interneurons disperse and survive in the recipient, where they differentiate chemically and morphologically and form functional inhibitory inputs onto recipient neurons. Remarkably, interneuron transplantation has been shown to improve seizure phenotypes in numerous models of epilepsy. Here, we describe this cellular approach for modifying epileptic neural circuits, while providing a neurosurgical perspective on some of the factors relevant to its therapeutic development.

\section{Development and Function of Cortical Interneurons}

Inhibitory interneurons constitute a heterogeneous cellular population, expressing a diversity of histochemical features, morphologies, physiological properties, and connectivities. Neocortical and hippocampal interneurons

ABBREVIATIONS CGE = caudal ganglionic eminence; MGE = medial ganglionic eminence; MTLE = mesial temporal lobe epilepsy; TLE = temporal lobe epilepsy. SUBMITTED December 1, 2019. ACCEPTED February 4, 2020.

INCLUDE WHEN CITING DOI: 10.3171/2020.2.FOCUS19955. 
primarily originate in the medial and caudal ganglionic eminence (MGE and CGE, respectively) of the embryonic ventral forebrain (Fig. 1). Unlike cortical excitatory neurons, which are produced locally, interneurons populate the cortex via long-distance tangential migration. From a basic organizational perspective, the MGE generates parvalbumin- and somatostatin-expressing interneurons, while the CGE generates vasoactive intestinal peptideexpressing interneurons. ${ }^{52}$ In the neocortex, CGE-derived interneurons provide inhibitory input onto other interneurons, while MGE-derived interneurons primarily inhibit excitatory neurons and CGE-derived interneurons. ${ }^{47,48}$ Interneurons primarily form local inhibitory projections that sculpt the spatial and temporal dynamics of excitatory input integration and action potential generation by their target cells. ${ }^{31}$ Interneurons also regulate synchronous network oscillatory patterns. ${ }^{7,55}$ Given their critical involvement in microcircuit and network function, interneuron pathologies give rise to numerous neuropsychiatric phenotypes, of which seizures are strikingly common. ${ }^{30}$

\section{Transplanted Interneurons Augment Synaptic Inhibition and Modify Recipient Neural Circuits}

When transplanted from the embryonic ganglionic eminence into various brain areas of the rodent, such as the neocortex, hippocampus, amygdala, striatum, and spinal cord, rodent primary interneuron precursors migrate several millimeters from injection sites (Fig. 2A and B) and develop morphologies characteristic of mature interneurons $^{1,5,41,71}$ (Fig. 2C). Transplanted interneuron precursors also express the inhibitory neurotransmitter, GABA, and they differentiate into histochemically defined subtypes of mature cortical interneurons.

Transplanted interneuron precursors form pre- and postsynaptic contacts with recipient neurons (Fig. 3A and $\mathrm{B})$, and they exhibit evoked excitatory potentials on recipient neuronal activation (Fig. 3C). ${ }^{27,33,56}$ Stimulation of transplanted interneurons likewise elicits inhibitory synaptic responses in recipient neurons. Transplanted MGE interneuron precursors dramatically augment synaptic inhibition onto recipient excitatory neurons, increasing the frequencies of inhibitory postsynaptic events by approximately 30\%-40\% $\%^{1,458}$ (Fig. 3D and E).

In addition to modulating inhibition at the cellular level, transplanted interneurons also elicit higher-order modifications of neural circuits. For example, interneuron transplantation into the visual cortex has been found to induce new periods of local ocular dominance plasticity, allowing for experience-dependent circuit reorganization. ${ }^{10,56}$ Transplantation into the amygdala likewise alters plasticity to promote the extinction of fear memories, without impairing memory formation. ${ }^{71}$ Finally, transplantation also modifies the synchrony of neural networks involving both local and remote brain regions..$^{26,66}$

While the preceding descriptions largely focus on the transplantation of rodent primary MGE cells, in vitro cell culture-derived interneuron populations exhibit similar potential to modify recipient synaptic inhibition and circuit function, as described below.

\section{Preclinical Studies of Interneuron Transplantation for Epilepsy}

Over the last 10 years, interneuron transplantation has been found to correct seizure phenotypes in preclinical rodent epilepsy models (Table 1). The first study of MGE cell transplantation as an epilepsy therapy involved injections of cells into neonatal mutant mice lacking a voltage-gated potassium channel. ${ }^{4}$ In this model of generalized epilepsy, transplanted interneurons survived and differentiated into mature interneurons, and they reduced recipient spontaneous seizure frequency by approximately $85 \%$ (Fig. 4A and B). In a second study using a genetic model of epilepsy with absence-like seizures, transplantation into the occipital cortex also reduced the frequency and duration of seizure events. ${ }^{20}$ Notably, in both models of generalized epilepsy, transplantation exerted corrective effects despite the fact that transplanted cells were primarily restricted to the recipient neocortex.

In acute seizure models, interneuron transplantation into the neocortex has been found to increase pharmacologically induced seizure thresholds ${ }^{6}$ and to reduce the power of electrically induced ictal discharges. ${ }^{11}$ Thus, in both acute seizure models and genetic epilepsy models, transplantation during neonatal stages provides seizureprotective effects in adulthood. However, these studies did not address whether transplantation corrects ongoing chronic forms of epilepsy, a question more relevant to clinical settings.

More recently, transplantation has been found to correct chronic seizure phenotypes in rodent models of temporal lobe epilepsy (TLE). In the pilocarpine-induced TLE model, transplanted MGE cells were found to differentiate into functional inhibitory interneurons in the hippocampus, reducing electrographic seizure frequency by $90 \%$ and correcting recipient aggression, hyperactivity, and spatial learning deficits. ${ }^{29}$ In a second study, transplantation into the adult dentate gyrus of pilocarpine-treated mice also reduced electrographic and behavioral measures of seizure activity, and it reduced dentate gyrus mossy fiber sprouting (Fig. 4C and D); transplantation into the lateral entorhinal cortex did not yield these corrective effects. ${ }^{23}$ Optogenetic stimulation of the transplant population elicited inhibitory synaptic responses in recipient dentate gyrus granule cells, indicating that the transplant population formed functional inhibitory synapses. More recently, hippocampal transplantation of interneurons derived from human pluripotent stem cells ${ }^{9}$ and induced pluripotent stem cells ${ }^{64}$ has also been found to improve seizure phenotypes and behavioral abnormalities in pharmacologically induced TLE models (Fig. 4D). By chemogenetically silencing the transplant population, one of these studies provided evidence that transplant activity was required for their seizure-modifying effects (Fig. 4E).

\section{Targeting Human Epilepsies With Interneuron Transplantation: Clinical and Network Considerations}

In translating interneuron transplantation from preclinical models toward the clinical settings, it is important to 


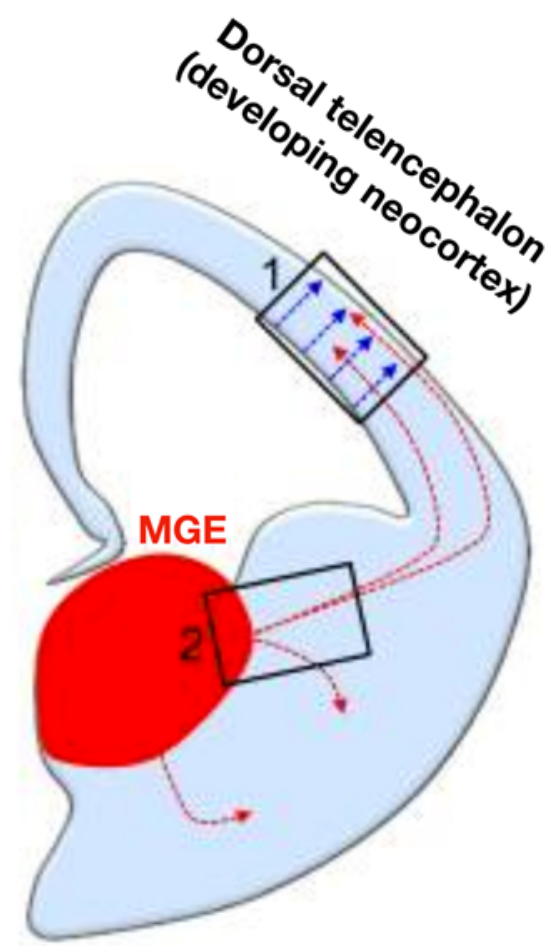

\section{Radial migration of excitatory neurons (1)}

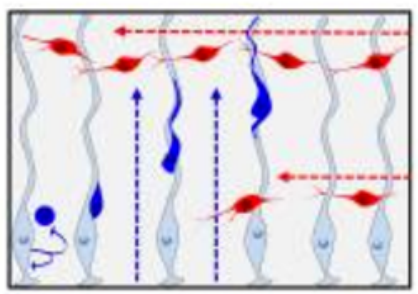

\section{Tangential migration of inhibitory interneurons (2)}

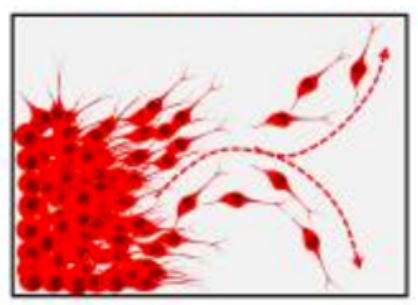

FIG. 1. The developmental origins of cortical interneurons. Cortical interneurons are generated during embryonic stages in the MGE and CGE of the embryonic ventral telencephalon (which forms into subcortical structures). From these origins, cortical interneurons undergo long-distance tangential migration into the developing dorsal telencephalon (which develops into the cerebral cortex), where they integrate into neural circuits with locally generated excitatory neurons. Adapted from Trends in Neuroscience, 37, Tyson JA, Anderson SA: GABAergic interneuron transplants to study development and treat disease, pp 169-177. Copyright 2014, with permission from Elsevier (Cell Press).

consider the following: 1) the variable nature of patient seizure networks, 2) the local and remote effects of transplantation on recipient neural circuits, and 3) the potential influences of the recipient physiological environment on the engraftment of transplanted interneurons. Epilepsies are classified as generalized, focal, or combined focal and generalized (or unidentified). Given that interneuron transplantation is best understood as a method for locally augmenting synaptic inhibition (Fig. 3C and D), it may be most effective for the treatment of well-localized focal epilepsies. This could include scenarios in which epileptogenic activity arises from within, or adjacent to, identified structural lesions such as mesial temporal sclerosis, malformations of cortical development, neoplasms, or vascular malformations (or to epileptogenic foci that do not exhibit a corresponding structural abnormality).

Focal lesional and nonlesional forms of epilepsy may be amenable to resective or ablative surgical approaches, but transplantation could yield a better balance of invasiveness, seizure control, and postoperative morbidities. Transplantation may also permit the treatment of focal seizures arising from eloquent regions, whereas resection and ablation cannot be safely performed without the high risk of neurological deficits. Based on early animal studies, transplantation into the primary visual cortex does not appear to elicit visual deficits, ${ }^{10}$ and gross motor function is unaffected by integration of transplanted interneurons into the motor cortex. ${ }^{65}$ Future animal studies should nonetheless further examine the safety and functional impacts of interneuron transplantation into eloquent areas.

In addition to targeting transplanted interneurons into or adjacent to a known seizure focus, transplantation could instead be directed remotely from an epileptogenic focus or foci. Moreover, it could also be applied to epilepsies in which a focus or foci cannot be localized a priori. This "network-based" approach to interneuron transplantation may be used to reduce the propagation of ictal activity, rather than directly suppressing an epileptogenic focus through local inhibitory synaptic effects. Theoretically, a network-based approach to transplantation could extend its application toward the treatment of generalized or poorly localizable epilepsies. While preclinical studies have demonstrated transplantation's local monosynaptic effects on recipient circuitry, $1,4,25,27,56,58,66$ future studies are expected to better examine its distributed, network-scale

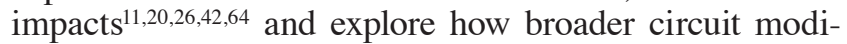
fications relate to the site of transplantation. Targeting interneurons to a critical, common seizure network node or "choke point," ${ }^{\prime \prime 6}$ or to a neuromodulatory center that broadly projects to cortical areas, could prove an effective method for treating both focal and generalized forms of epilepsy. ${ }^{21,36}$

Finally, the recipient background may influence the cellular development and circuit integration of transplanted interneurons. Epilepsies arise from numerous etiologies, including structural, genetic, infectious, immune, and met- 


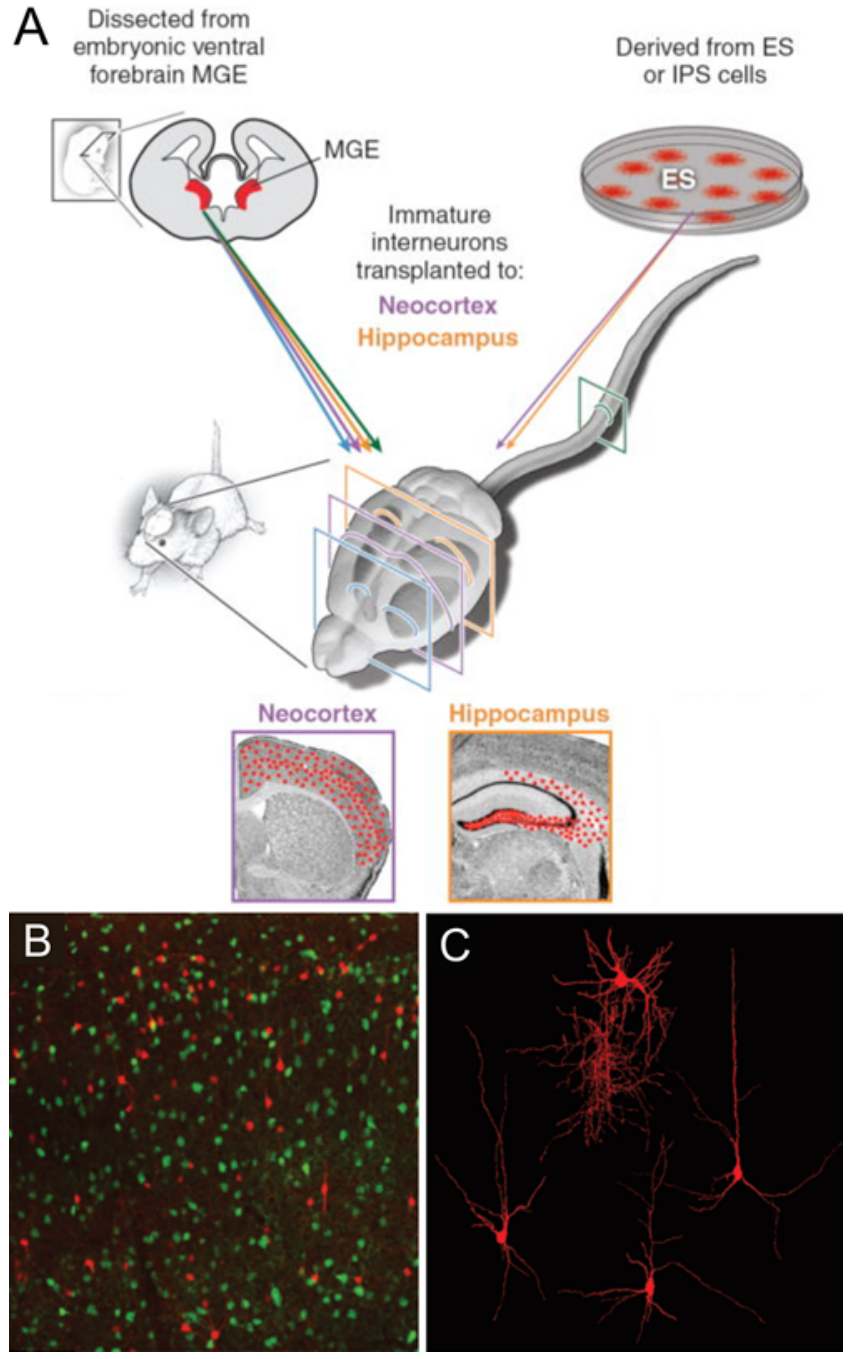

FIG. 2. Transplanted immature interneurons disperse in recipient brain parenchyma. A: Donor interneuron populations can be harvested directly from the embryonic MGE or produced from stem cells in vitro. B: When transplanted from these sources into the recipient central nervous system, immature interneuron populations (red) disperse and survive, augmenting native interneuron populations (green). C: Transplanted interneurons express histochemical markers and develop morphologies characteristic of mature inhibitory interneurons. ES = embryonic stem; IPS = induced pluripotent stem. From Southwell DG, Nicholas CR, Basbaum Al, Stryker MP, Kriegstein AR, Rubenstein JL, et al: Interneurons from embryonic development to cell-based therapy. Science 344:1240622, 2014. Reprinted with permission from AAAS.

abolic ones. ${ }^{53}$ In some cases, the primary etiologic process is self-limited or correctable (e.g., a neonatal infection or a resectable brain lesion), whereas in others, the epileptogenic process is intractable or persistent (e.g., a genetic/ syndromic epilepsy). If the pathogenetic process is ongoing at the time of transplantation, it could influence the engraftment and resultant circuit effects of the transplant population. For example, transplanted interneurons may not be able to migrate or extend projections within structural lesions, which could reduce their ability to increase synaptic inhibition in or around such areas. Likewise, diffuse processes, such as autoimmune hyperactivity or met- abolic derangements, might create conditions that restrict the functional integration of transplant populations. Additionally, rodent neurogenesis studies suggest that ongoing and remote seizure activities shape the morphological and electrophysiological differentiation of immature neurons as they integrate into neural circuits. ${ }^{45,49}$ For these reasons, transplantation may prove most effective if timed after the cessation of the primary pathogenetic process underlying the epilepsy or if performed during certain periods of waxing or waning seizure frequency.

\section{Obtaining Interneurons for Human Clinical Applications}

To advance interneuron transplantation from preclinical animal studies toward human clinical settings, appropriate donor cell populations must be identified. It has been assumed that future clinical applications will require the use of human interneuron cell types. Because of ethical and technical constraints to using primary human cell populations, cell culture methods have been developed to produce MGE-like populations from human pluripotent stem cells, $, 38,44$ embryonic stem cells, ${ }^{15,17,40}$ and induced pluripotent stem cells ${ }^{64}$ However, the production of interneurons in vitro is limited by its relatively low yield and significant cost. In some cases, these systems produce cell populations of mixed composition (neurons and glia) with limited migratory potential.9,35,40,57,64 Also, human stem cell-derived interneuron populations mature slowly in the recipient brain, following protracted, human developmental timescales, ${ }^{44}$ which could delay or reduce their therapeutic efficacy. Notably, in vitro-derived interneuron populations do not form neoplasms or elicit significant immune responses in the rodent recipient brain, though immunosuppressive methods have been used to reduce recipient immunoreactivity in human-to-rodent transplantation studies. $9,44,64$ Altogether, a growing understanding of interneuron development, combined with improved cell and tissue engineering methodologies, is expected to improve the generation of cellular populations for clinical purposes.

As an alternative to human in vitro-derived cell populations, primary cells from animals, such as pigs or rodents, could potentially be used for transplantation into humans. As mentioned above, human-derived interneuron populations can therapeutically integrate into the epileptic mouse brain. These findings suggest that sufficient homology exists between nonhuman and human cells such that the cellular populations can interact in a physiologically corrective manner., ${ }^{9,64}$ Primary MGE cells from animals might represent a more efficient and tractable donor cell population than human in vitro-derived cells. For example, there is a wealth of well-characterized transgenic mouse lines that could enable selection of specific donor cell types and the subsequent and physiological modulation of the transplant population in the human recipient. Such an approach would require additional study of the immunogenicity of xenotransplanted cells and could necessitate recipient immunosuppression. Future nonhuman xenotransplantation studies (e.g., porcine to nonhuman primate) may be used to assess the safety and therapeutic efficacy of such approaches. 

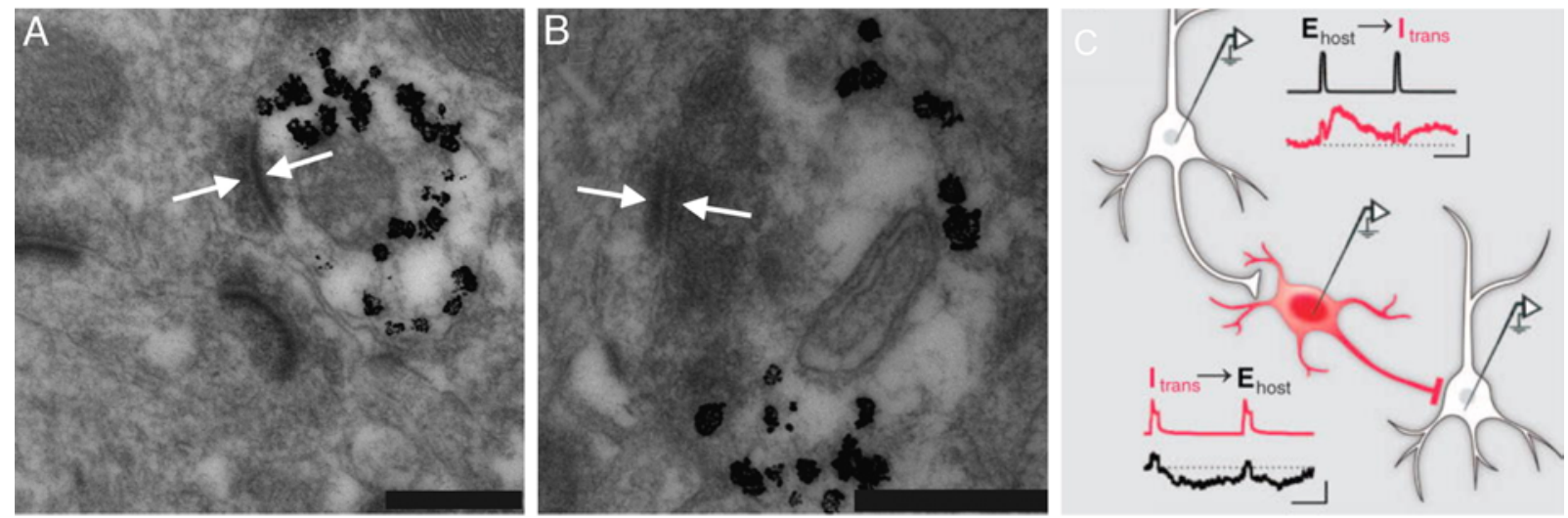

D Control (media vehicle; Con)

$\mathrm{E}$

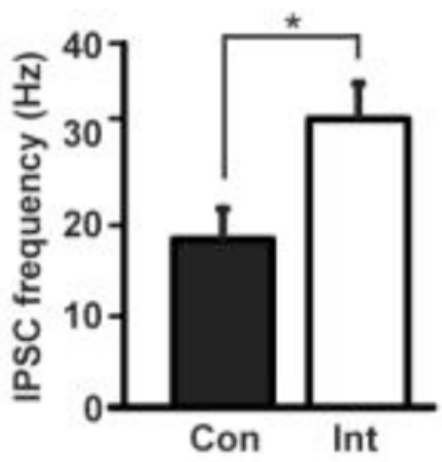

FIG. 3. Transplanted interneurons form functional inhibitory synapses onto recipient neurons. A and B: Transplanted interneurons, identified by gold particle-conjugated antibodies against a donor-specific marker (black densities), receive synaptic inputs from recipient neurons $(A)$ and form synaptic inputs onto recipient neurons (B; arrows). C: Simultaneous electrode recordings from transplanted interneurons (red) and recipient excitatory neurons (white). Stimulation of recipient excitatory neurons elicits excitatory postsynaptic potentials in the transplanted interneuron $\left(E_{\text {host }}\right.$ to $\left.I_{\text {trans }}\right)$, while depolarization of the transplanted interneuron elicits inhibitory postsynaptic potentials in the recipient excitatory neuron (Itrans to $_{E_{\text {host }}}$. D: Spontaneous inhibitory postsynaptic current traces recorded from excitatory neurons in adult mice that received cortical transplants of MGE interneuron precursors (Int) or control injections (Con) as neonates. E: Transplanted interneurons increase the frequency of spontaneous inhibitory synaptic events in recipient excitatory neurons. A and B: Scale bars $=200 \mu \mathrm{m}$. D: Horizontal bar $=200 \mathrm{msec}$; vertical bar $=40 \mathrm{pA}$. E: Asterisk indicates $p<0.05$ by Wilcoxon rank-sum test. Images adapted from Baraban et al., $2009^{4}$ (A and B); Southwell et al., $2014^{57}$ (C; from Southwell DG, Nicholas CR, Basbaum Al, Stryker MP, Kriegstein AR, Rubenstein JL, et al: Interneurons from embryonic development to cell-based therapy. Science 344:1240622, 2014. Reprinted with permission from AAAS); and Southwell et al., $2012^{58}$ (D and E; reprinted by permission from Springer Nature, Nature:58 Intrinsically determined cell death of developing cortical interneurons, Southwell DG, Paredes MF, Galvao RP, Jones DL, Froemke RC, Sebe JY, et al., copyright 2012).

\section{Delivering Interneurons to the Human Brain}

In preclinical rodent studies, transplanted interneurons have been introduced directly into the brain parenchyma through straight needles or cannulas. In neonatal recipients, mouse and human transplant populations have been found to populate areas up to $1-4 \mathrm{~mm}$ from the injection site. ${ }^{1,44}$ In adult recipients, transplanted interneurons are dispersed over shorter distances ${ }^{67}$ because, unlike the neonatal recipient brain parenchyma, the adult brain does not expand and displace the transplant population along with itself. Moreover, the adult brain is less permissive to cellular migration. Adult human clinical applications may thus necessitate cellular injections into numerous sites to adequately distribute the transplant population. In such a scenario, the use of straight needles could subject the patient to multiple brain penetrations, each carrying the risk of vascular and parenchymal injury. To minimize the risks of brain penetration while achieving adequate transplant distribution, next-generation injection systems, such as radially branching devices, ${ }^{54}$ may prove necessary.

It also remains unclear as to how the transplanted cell number should be adjusted from rodent to human scales. Rodent studies suggest that maximal transplant-mediated inhibition is reached with relatively small transplant sizes, ${ }^{11,58}$ suggesting that tissue coverage with a relatively low transplant density may be sufficient for therapeutic effects. In addition to its increased size, the human brain exhibits greater structural complexity than the rodent brain. For example, while interneuron transplantation has been characterized in the lissencephalic rodent neocortex (which does not contain gyri and sulci), it is unknown how transplanted interneurons may migrate and synaptically integrate in the folded human neocortex. ${ }^{62}$ Future studies should thus examine the integration of transplanted interneurons in species that better model the size and anatomical conformation of the human brain. 


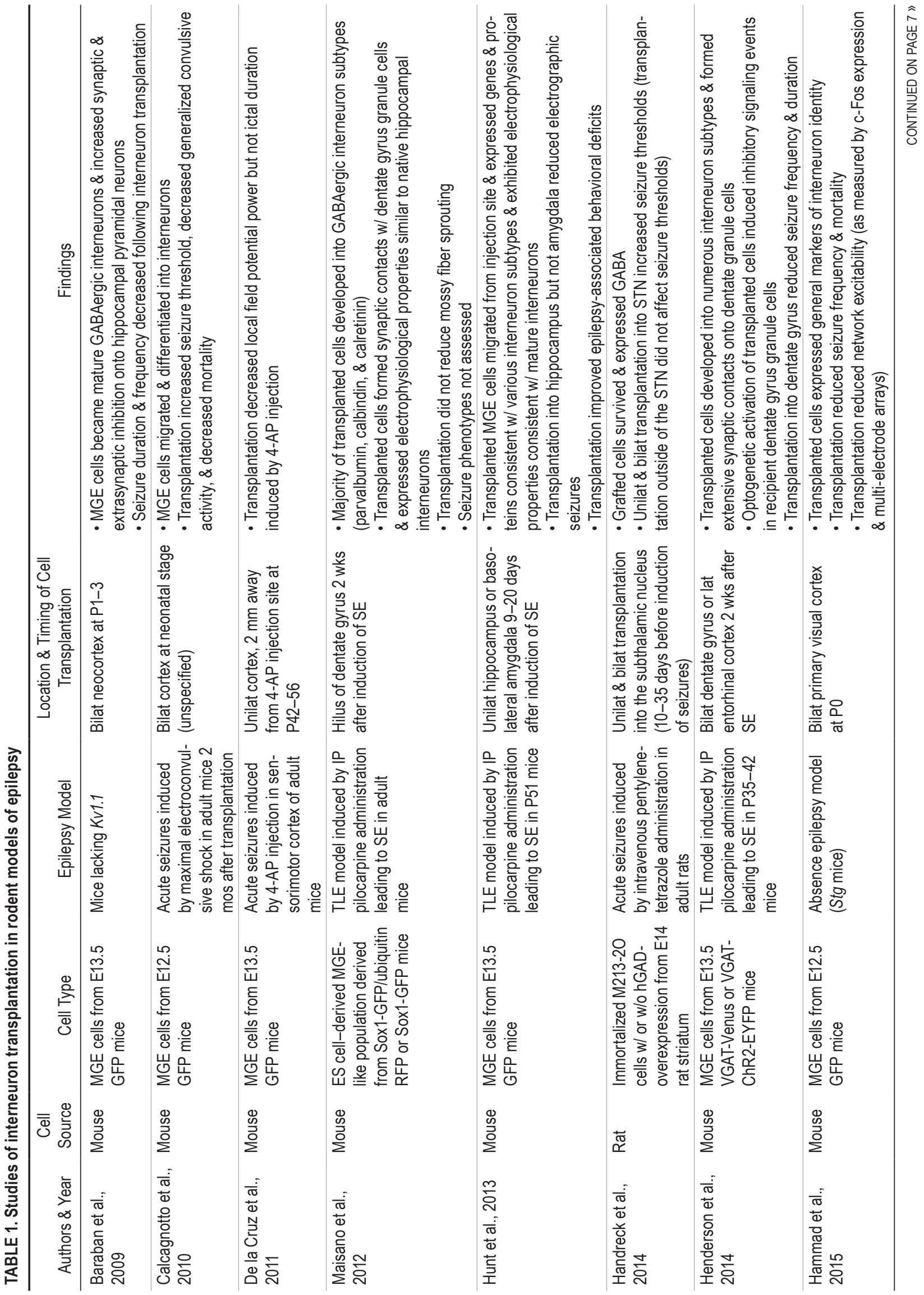


Additionally, technical aspects of cellular delivery must be further resolved to optimize future clinical applications. ${ }^{2}$ Numerous procedural factors determine the successful targeting of cells and biological agents into the nervous system, including cannula material and shape, ${ }^{32,61,72}$ cell suspension vehicle, ${ }^{51}$ cell density, ${ }^{51}$ injection rate, ${ }^{32}$ injection volume,${ }^{19}$ and tissue compliance at the injection site. ${ }^{18}$ These parameters must be accounted for and evaluated in future preclinical studies of interneuron transplantation. Finally, to visually monitor and assess the targeting of the transplant population, interventional MRI-based approaches may be used to inject contrast-labeled cell suspensions. ${ }^{22}$

\section{Future Preclinical Studies to Advance the Efficacy of Interneuron Transplantation}

The clinical potential of interneuron transplantation may be further expanded through novel strategies for selecting and tracking transplant populations and for controlling their physiological activity in the recipient. Due to the specificities of their afferent and efferent projections, as well as distinct intrinsic responses to synaptic inputs, distinct interneuron subpopulations differentially contribute to inhibition. When transplanted into wild-type recipients, interneuron precursors appear to integrate into neural circuits in manners consistent with their native configurations. As different forms of inhibition play distinct roles in neural circuit excitatory-inhibitory balance and seizure formation, future studies may be directed toward examining the disease-modifying effects of subtype-restricted donor populations. . $^{12,34,69}$

Further advances may also allow for monitoring transplant cellular dispersion and controlling transplant activity in the recipient. For example, bioluminescence imaging of transplant populations, ${ }^{3}$ or MRI ${ }^{39}$ could allow noninvasive visualization of transplant dispersion and engraftment. Additionally, transplantation of cells with modified intrinsic physiological properties may allow for the optimization of transplanted cell physiology with respect to recipient circuit function. ${ }^{42}$ Additionally, transplant populations may be engineered to deliver trophic or neuroprotective agents. They may also be designed to express light- or chemically sensitive ion channels or transporters, allowing for optogenetic $^{9,24,27}$ and chemogenetic ${ }^{64}$ control of transplant activity. Finally, donor populations may also be engineered to express inducible cytotoxins, allowing the ablation of transplanted cells. ${ }^{60}$ This approach may provide a safety mechanism should transplantation exert unexpected behavioral effects.

\section{Ethical Considerations}

The ethical concerns surrounding cellular therapies have largely focused on the sourcing of donor cell populations, particularly those collected from human embryos or fetuses. ${ }^{50}$ As discussed above, however, interneuron populations can be generated from human pluripotent and embryonic stem cell lines and induced pluripotent stem cells, thus circumventing some of these ethical issues. What remains a larger concern is ensuring that clinical trials of interneuron transplantation adhere to fundamental ethical 

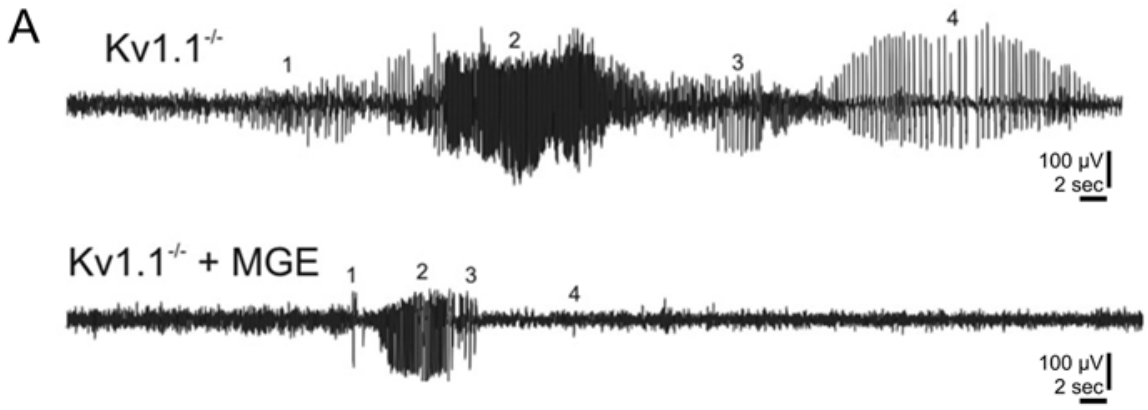

B

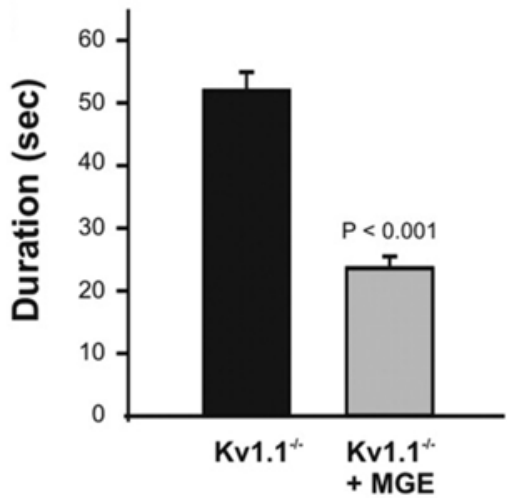

C

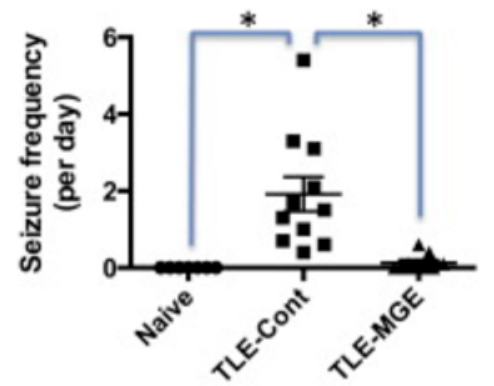

D

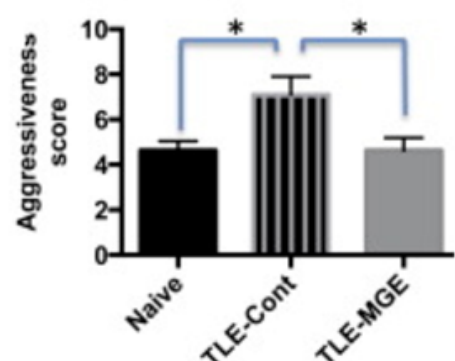

E
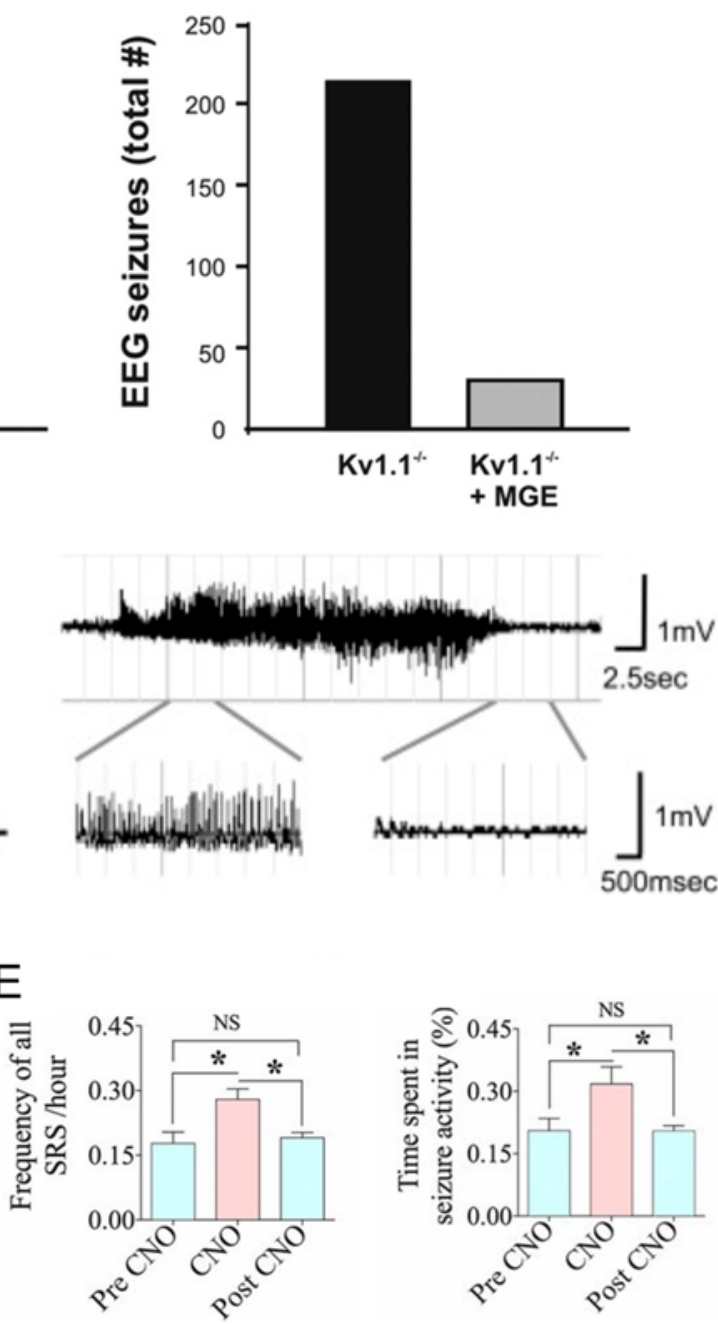

FIG. 4. The transplantation of rodent MGE interneuron precursors, or interneuron populations derived from human stem cells in vitro, modified seizure phenotypes in rodent models of generalized and focal epilepsy. A: Electrographic traces of spontaneous seizures recorded from adult Kv1.1 mutant mice (a genetic model of generalized epilepsy) that received dead-cell control injections (upper) or MGE interneuron transplants (lower) into the neocortex as neonates. B and C: Interneuron transplantation significantly reduced seizure duration (B) and frequency (C) in Kv1.1 recipients. The transplantation of adult pluripotent stem cell-derived interneurons into adult mice with pilocarpine-induced epilepsy (an injury model of TLE [TLE-MGE]) reduced the frequency (left) of recipient electrographic seizures (right), as compared to control injections (TLE-Cont). D: Transplantation also improved associated behavioral abnormalities in the pilocarpine model of TLE, such as recipient aggressiveness. E: In the pilocarpine model of TLE, chemogenetic silencing of transplant populations (derived from induced pluripotent stem cells) blocked the seizure-suppressive effects of interneuron transplantation (CNO), as measured by electroencephalography. C-E: $p<0.05$ by ANOVA; NS = not statistically significant. Adapted from Baraban et al., $2009^{4}$ (A and B); Cunningham et al., $2014^{9}$ (C and D; reprinted from Cell Stem Cell, 15, Cunningham M, Cho JH, Leung A, Savvidis G, Ahn S, Moon M, et al: hPSC-derived maturing GABAergic interneurons ameliorate seizures and abnormal behavior in epileptic mice, pp 559-573, copyright 2014, with permission from Elsevier); and Upadhya et al., $2019^{64}$ (E; copyright 2019 Upadhya D, Hattiangady B, Castro OW, Shuai B, Kodali M, Attaluri S, et al. CC BY-NCND 4.0 [https://creativecommons.org/licenses/by-nc-nd/4.0/]). 
principles of human research, including respect for subjects and their autonomy, non-maleficence, beneficence, and justice.

Informed consent is fundamental to ensuring patient autonomy, and research subjects must be given sufficient information to understand the potential risks and benefits of an experimental therapy. In the case of interneuron transplantation, these potential risks and benefits can at first only be extrapolated from animal studies and related human studies involving other cell types. As mentioned above, researchers of rodent preclinical transplantation studies have not observed adverse effects such as transplant tumorigenicity, host inflammatory response, or sensorimotor impairments. Moreover, transplantation was found to correct some behavioral abnormalities associated with epilepsy, and adverse behavioral effects were not observed. Nonetheless, animal studies cannot fully model the effects of interneuron transplantation in humans, and preclinical animal studies should continue to assess for adverse outcomes to the extent possible. These inherent uncertainties and shortcomings must be considered in the design and presentation of clinical trials. In turn, clinical trials should be focused on epilepsy conditions that, based on preclinical studies, may respond most favorably to interneuron transplantation. Such approaches will optimize - to the degree possible - the inherently uncertain risk-to-benefit ratio of this prospective therapy.

Additionally, consideration must be given to the selection of appropriate controls for studies of transplant efficacy. Placebo controls used in animal studies of interneuron transplantation, such as acellular vehicle injections, would expose patients to risk without offering known potential benefit; thus, the use of active controls (e.g., laser ablation, which, like cell injection, would involve a small craniotomy and device deployment into the brain) or slightly invasive placebos (e.g., drilling a partial-thickness burr hole) may be more appropriate for efficacy studies in humans. ${ }^{43}$

\section{A Candidate Clinical Trial: Interneuron Transplantation for MTLE}

Based on demographic, anatomical, and network considerations, MTLE likely represents the most tractable setting for initial human studies of interneuron transplantation. MTLE is currently the most common indication for resective and ablative epilepsy surgeries, ${ }^{14}$ yet in $30 \%-50 \%$ of treated patients, these techniques do not yield seizure freedom, and they pose the risk of adverse morbidities such as verbal memory impairment, language disturbance, and visual field loss. ${ }^{68,70}$ Interneuron transplantation, as a regenerative rather than destructive approach, may prove a less morbid treatment for MTLE. Moreover, MTLE is associated with hippocampal interneuron cytopathology and inhibitory hypofunction, ${ }^{16}$ which can be corrected or compensated for by interneuron transplantation. Additionally, as mentioned above, interneuron transplantation has been most extensively studied in rodent models of MTLE. $9,23,28,37,64$

Pilot studies in humans should be designed to provide an initial assessment of the safety of interneuron transplantation, while generating insights that can shape subse- quent efficacy studies. To approach these ends, we propose studying transplantation in patients with mesial temporal sclerosis who experience seizures localized to the nondominant temporal lobe. We propose using stereotactic or interventional MRI-based techniques to make cellular injections into the mesial temporal lobe along an occipital trajectory, similar to that used for selective laser amygdalohippocampectomy. Using this method, injections would be made into the amygdala, hippocampal head, and hippocampal body. We favor this population and surgical approach because, should transplantation elicit unexpected adverse effects, temporal lobectomy (the gold standard surgical treatment for nondominant MTLE) would remain a backstop for 1) treating ongoing or worsening seizures and 2) minimizing or controlling potential adverse effects of transplantation (by removing the tissue populated with transplanted cells).

Following transplantation, recipient patients would undergo interval neurological and neuropsychological testing to assess the safety and functional impacts of transplantation. Additionally, blood and cerebrospinal fluid studies would be performed to assess recipient inflammatory responses, and MRI would be used to monitor for unwanted structural effects, such as teratoma formation, demyelination, and hemorrhage. While first-in-human studies would not be designed to thoroughly assess transplant efficacy, information on recipient seizure burden, medication requirements, and quality of life measurements would also be gathered. After completing 12-24 months of observation, patients could electively undergo further surgical treatment (i.e., anterior temporal lobectomy). During resection, the amygdala and hippocampus would be removed en bloc to allow for subsequent ex vivo histological and electrophysiological studies.

\section{Conclusions}

Interneuron transplantation represents a novel cellbased strategy for modifying synaptic inhibition and neural circuit function. In rodent models of epilepsy, transplantation of mouse or human interneuron populations improves recipient seizure phenotypes and associated behavioral abnormalities. To effectively direct interneuron transplantation as an epilepsy therapy, preclinical translational studies should further examine where, when, and which interneurons should be transplanted to provide optimal therapeutic effects. Future preclinical studies should also be designed to account for the advanced scale and structural complexity of the human brain, the diverse network features of human epilepsies, and the potential systemic and behavioral impacts of transplantation. Together, these efforts will advance interneuron transplantation from animal models toward human clinical settings, where interneuron transplantation may ultimately expand the surgical treatment of epilepsy and other neurological disorders.

\section{References}

1. Alvarez-Dolado M, Calcagnotto ME, Karkar KM, Southwell DG, Jones-Davis DM, Estrada RC, et al: Cortical inhibition modified by embryonic neural precursors grafted into the postnatal brain. J Neurosci 26:7380-7389, 2006 
2. Amer MH, Rose FRAJ, Shakesheff KM, Modo M, White LJ: Translational considerations in injectable cell-based therapeutics for neurological applications: concepts, progress and challenges. NPJ Regen Med 2:23, 2017

3. Aswendt M, Vogel S, Schäfer C, Jathoul A, Pule M, Hoehn M: Quantitative in vivo dual-color bioluminescence imaging in the mouse brain. Neurophotonics 6:025006, 2019

4. Baraban SC, Southwell DG, Estrada RC, Jones DL, Sebe JY, Alfaro-Cervello C, et al: Reduction of seizures by transplantation of cortical GABAergic interneuron precursors into Kv1.1 mutant mice. Proc Natl Acad Sci U S A 106:15472-15477, 2009

5. Bráz JM, Sharif-Naeini R, Vogt D, Kriegstein A, AlvarezBuylla A, Rubenstein JL, et al: Forebrain GABAergic neuron precursors integrate into adult spinal cord and reduce injuryinduced neuropathic pain. Neuron 74:663-675, 2012

6. Calcagnotto ME, Ruiz LP, Blanco MM, Santos-Junior JG, Valente MF, Patti C, et al: Effect of neuronal precursor cells derived from medial ganglionic eminence in an acute epileptic seizure model. Epilepsia 51 (Suppl 3):71-75, 2010

7. Cardin JA, Carlén M, Meletis K, Knoblich U, Zhang F, Deisseroth K, et al: Driving fast-spiking cells induces gamma rhythm and controls sensory responses. Nature 459:663667,2009

8. Chang BS, Lowenstein DH: Epilepsy. N Engl J Med 349:1257-1266, 2003

9. Cunningham M, Cho JH, Leung A, Savvidis G, Ahn S, Moon $\mathrm{M}$, et al: hPSC-derived maturing GABAergic interneurons ameliorate seizures and abnormal behavior in epileptic mice. Cell Stem Cell 15:559-573, 2014

10. Davis MF, Figueroa Velez DX, Guevarra RP, Yang MC, Habeeb M, Carathedathu MC, et al: Inhibitory neuron transplantation into adult visual cortex creates a new critical period that rescues impaired vision. Neuron 86:1055-1066, 2015

11. De la Cruz E, Zhao M, Guo L, Ma H, Anderson SA, Schwartz TH: Interneuron progenitors attenuate the power of acute focal ictal discharges. Neurotherapeutics 8:763-773, 2011

12. Donegan JJ, Tyson JA, Branch SY, Beckstead MJ, Anderson SA, Lodge DJ: Stem cell-derived interneuron transplants as a treatment for schizophrenia: preclinical validation in a rodent model. Mol Psychiatry 22:1492-1501, 2017

13. Engel J Jr: Approaches to refractory epilepsy. Ann Indian Acad Neurol 17 (Suppl 1):S12-S17, 2014

14. Englot DJ: A modern epilepsy surgery treatment algorithm: incorporating traditional and emerging technologies. Epilepsy Behav 80:68-74, 2018

15. Germain ND, Banda EC, Becker S, Naegele JR, Grabel LB: Derivation and isolation of NKX2.1-positive basal forebrain progenitors from human embryonic stem cells. Stem Cells Dev 22:1477-1489, 2013

16. Goldberg EM, Coulter DA: Mechanisms of epileptogenesis: a convergence on neural circuit dysfunction. Nat Rev Neurosci 14:337-349, 2013

17. Goulburn AL, Stanley EG, Elefanty AG, Anderson SA: Generating GABAergic cerebral cortical interneurons from mouse and human embryonic stem cells. Stem Cell Res (Amst) 8:416-426, 2012

18. Guest J, Benavides F, Padgett K, Mendez E, Tovar D: Technical aspects of spinal cord injections for cell transplantation. Clinical and translational considerations. Brain Res Bull 84:267-279, 2011

19. Gutierrez J, Lamanna JJ, Grin N, Hurtig CV, Miller JH, Riley $\mathrm{J}$, et al: Preclinical validation of multilevel intraparenchymal stem cell therapy in the porcine spinal cord. Neurosurgery 77:604-612, 2015

20. Hammad M, Schmidt SL, Zhang X, Bray R, Frohlich F, Ghashghaei HT: Transplantation of GABAergic interneurons into the neonatal primary visual cortex reduces absence seizures in stargazer mice. Cereb Cortex 25:2970-2979, 2015

21. Handreck A, Backofen-Wehrhahn B, Bröer S, Löscher W, Gernert M: Anticonvulsant effects by bilateral and unilateral transplantation of GABA-producing cells into the subthalamic nucleus in an acute seizure model. Cell Transplant 23:111-132, 2014

22. Heiss JD, Lungu C, Hammoud DA, Herscovitch P, Ehrlich DJ, Argersinger DP, et al: Trial of magnetic resonance-guided putaminal gene therapy for advanced Parkinson's disease. Mov Disord 34:1073-1078, 2019

23. Henderson KW, Gupta J, Tagliatela S, Litvina E, Zheng X, Van Zandt MA, et al: Long-term seizure suppression and optogenetic analyses of synaptic connectivity in epileptic mice with hippocampal grafts of GABAergic interneurons. J Neurosci 34:13492-13504, 2014

24. Hoseini MS, Rakela B, Flores-Ramirez Q, Hasenstaub AR, Alvarez-Buylla A, Stryker MP: Transplanted cells are essential for the induction but not the expression of cortical plasticity. J Neurosci 39:7529-7538, 2019

25. Howard MA, Baraban SC: Synaptic integration of transplanted interneuron progenitor cells into native cortical networks. J Neurophysiol 116:472-478, 2016

26. Howard MA, Rubenstein JLR, Baraban SC: Bidirectional homeostatic plasticity induced by interneuron cell death and transplantation in vivo. Proc Natl Acad Sci U S A 111:492497, 2014

27. Hsieh JY, Baraban SC: Medial ganglionic eminence progenitors transplanted into hippocampus integrate in a functional and subtype-appropriate manner. eNeuro 4:1-17, 2017

28. Hunt RF, Baraban SC: Interneuron transplantation as a treatment for epilepsy. Cold Spring Harb Perspect Med 5:a022376, 2015

29. Hunt RF, Girskis KM, Rubenstein JL, Alvarez-Buylla A, Baraban SC: GABA progenitors grafted into the adult epileptic brain control seizures and abnormal behavior. Nat Neurosci 16:692-697, 2013

30. Katsarou AM, Moshé SL, Galanopoulou AS: Interneuronopathies and their role in early life epilepsies and neurodevelopmental disorders. Epilepsia Open 2:284-306, 2017

31. Kepecs A, Fishell G: Interneuron cell types are fit to function. Nature 505:318-326, 2014

32. Kondziolka D, Gobbel GT, Fellows-Mayle W, Chang YF, Uram M: Injection parameters affect cell viability and implant volumes in automated cell delivery for the brain. Cell Transplant 20:1901-1906, 2011

33. Larimer P, Spatazza J, Espinosa JS, Tang Y, Kaneko M, Hasenstaub AR, et al: Caudal ganglionic eminence precursor transplants disperse and integrate as lineage-specific interneurons but do not induce cortical plasticity. Cell Rep 16:1391-1404, 2016

34. Larimer P, Spatazza J, Stryker MP, Alvarez-Buylla A, Hasenstaub AR: Development and long-term integration of MGE-lineage cortical interneurons in the heterochronic environment. J Neurophysiol 118:131-139, 2017

35. Liu Y, Liu H, Sauvey C, Yao L, Zarnowska ED, Zhang SC: Directed differentiation of forebrain GABA interneurons from human pluripotent stem cells. Nat Protoc 8:1670-1679, 2013

36. Liu Y, Weick JP, Liu H, Krencik R, Zhang X, Ma L, et al: Medial ganglionic eminence-like cells derived from human embryonic stem cells correct learning and memory deficits. Nat Biotechnol 31:440-447, 2013

37. Löscher W, Ebert U, Lehmann H, Rosenthal C, Nikkhah G: Seizure suppression in kindling epilepsy by grafts of fetal GABAergic neurons in rat substantia nigra. J Neurosci Res 51:196-209, 1998 
38. Maisano X, Litvina E, Tagliatela S, Aaron GB, Grabel LB, Naegele JR: Differentiation and functional incorporation of embryonic stem cell-derived GABAergic interneurons in the dentate gyrus of mice with temporal lobe epilepsy. $\mathbf{J}$ Neurosci 32:46-61, 2012

39. Mallett CL, Shuboni-Mulligan DD, Shapiro EM: Tracking neural progenitor cell migration in the rodent brain using magnetic resonance imaging. Front Neurosci 12:995, 2019

40. Maroof AM, Keros S, Tyson JA, Ying SW, Ganat YM, Merkle FT, et al: Directed differentiation and functional maturation of cortical interneurons from human embryonic stem cells. Cell Stem Cell 12:559-572, 2013

41. Martínez-Cerdeño V, Noctor SC, Espinosa A, Ariza J, Parker P, Orasji S, et al: Embryonic MGE precursor cells grafted into adult rat striatum integrate and ameliorate motor symptoms in 6-OHDA-lesioned rats. Cell Stem Cell 6:238250, 2010

42. Martinez-Losa M, Tracy TE, Ma K, Verret L, ClementePerez A, Khan AS, et al: Nav1.1-overexpressing interneuron transplants restore brain rhythms and cognition in a mouse model of Alzheimer's disease. Neuron 98:75-89.e5, 2018

43. Master Z, McLeod M, Mendez I: Benefits, risks and ethical considerations in translation of stem cell research to clinical applications in Parkinson's disease. J Med Ethics 33:169173,2007

44. Nicholas CR, Chen J, Tang Y, Southwell DG, Chalmers N, Vogt D, et al: Functional maturation of hPSC-derived forebrain interneurons requires an extended timeline and mimics human neural development. Cell Stem Cell 12:573586, 2013

45. Overstreet-Wadiche LS, Bromberg DA, Bensen AL, Westbrook GL: Seizures accelerate functional integration of adultgenerated granule cells. J Neurosci 26:4095-4103, 2006

46. Paz JT, Huguenard JR: Microcircuits and their interactions in epilepsy: is the focus out of focus? Nat Neurosci 18:351-359, 2015

47. Pfeffer CK, Xue M, He M, Huang ZJ, Scanziani M: Inhibition of inhibition in visual cortex: the logic of connections between molecularly distinct interneurons. Nat Neurosci 16:1068-1076, 2013

48. Pi HJ, Hangya B, Kvitsiani D, Sanders JI, Huang ZJ, Kepecs A: Cortical interneurons that specialize in disinhibitory control. Nature 503:521-524, 2013

49. Raijmakers M, Clynen E, Smisdom N, Nelissen S, Brône B, Rigo JM, et al: Experimental febrile seizures increase dendritic complexity of newborn dentate granule cells. Epilepsia 57:717-726, 2016

50. Ramos-Zúñiga R, González-Pérez O, Macías-Ornelas A, Capilla-González V, Quiñones-Hinojosa A: Ethical implications in the use of embryonic and adult neural stem cells. Stem Cells Int 2012:470949, 2012

51. Rossetti T, Nicholls F, Modo M: Intracerebral cell implantation: preparation and characterization of cell suspensions. Cell Transplant 25:645-664, 2016

52. Rudy B, Fishell G, Lee S, Hjerling-Leffler J: Three groups of interneurons account for nearly $100 \%$ of neocortical GABAergic neurons. Dev Neurobiol 71:45-61, 2011

53. Scheffer IE, Berkovic S, Capovilla G, Connolly MB, French J, Guilhoto L, et al: ILAE classification of the epilepsies: position paper of the ILAE Commission for Classification and Terminology. Epilepsia 58:512-521, 2017

54. Silvestrini MT, Yin D, Coppes VG, Mann P, Martin AJ, Larson PS, et al: Radially branched deployment for more efficient cell transplantation at the scale of the human brain. Stereotact Funct Neurosurg 91:92-103, 2013

55. Sohal VS, Zhang F, Yizhar O, Deisseroth K: Parvalbumin neurons and gamma rhythms enhance cortical circuit performance. Nature 459:698-702, 2009

56. Southwell DG, Froemke RC, Alvarez-Buylla A, Stryker MP,
Gandhi SP: Cortical plasticity induced by inhibitory neuron transplantation. Science 327:1145-1148, 2010

57. Southwell DG, Nicholas CR, Basbaum AI, Stryker MP, Kriegstein AR, Rubenstein JL, et al: Interneurons from embryonic development to cell-based therapy. Science 344:1240622, 2014

58. Southwell DG, Paredes MF, Galvao RP, Jones DL, Froemke $\mathrm{RC}$, Sebe JY, et al: Intrinsically determined cell death of developing cortical interneurons. Nature 491:109-113, 2012

59. Staley K: Molecular mechanisms of epilepsy. Nat Neurosci 18:367-372, 2015

60. Tang Y, Stryker MP, Alvarez-Buylla A, Espinosa JS: Cortical plasticity induced by transplantation of embryonic somatostatin or parvalbumin interneurons. Proc Natl Acad Sci U S A 111:18339-18344, 2014

61. Torres EM, Trigano M, Dunnett SB: Translation of cell therapies to the clinic: characteristics of cell suspensions in large-diameter injection cannulae. Cell Transplant 24:737749,2015

62. Tsintou M, Dalamagkas K, Makris N: Taking central nervous system regenerative therapies to the clinic: curing rodents versus nonhuman primates versus humans. Neural Regen Res 15:425-437, 2020

63. Tyson JA, Anderson SA: GABAergic interneuron transplants to study development and treat disease. Trends Neurosci 37:169-177, 2014

64. Upadhya D, Hattiangady B, Castro OW, Shuai B, Kodali M, Attaluri S, et al: Human induced pluripotent stem cellderived MGE cell grafting after status epilepticus attenuates chronic epilepsy and comorbidities via synaptic integration. Proc Natl Acad Sci U S A 116:287-296, 2019

65. Valente MF, Romariz S, Calcagnotto ME, Ruiz L, Mello LE, Frussa-Filho R, et al: Postnatal transplantation of interneuronal precursor cells decreases anxiety-like behavior in adult mice. Cell Transplant 22:1237-1247, 2013

66. Verret L, Mann EO, Hang GB, Barth AM, Cobos I, Ho K, et al: Inhibitory interneuron deficit links altered network activity and cognitive dysfunction in Alzheimer model. Cell 149:708-721, 2012

67. Wichterle H, Garcia-Verdugo JM, Herrera DG, AlvarezBuylla A: Young neurons from medial ganglionic eminence disperse in adult and embryonic brain. Nat Neurosci 2:461466, 1999

68. Wiebe S, Blume WT, Girvin JP, Eliasziw M: A randomized, controlled trial of surgery for temporal-lobe epilepsy. N Engl J Med 345:311-318, 2001

69. Wonders CP, Taylor L, Welagen J, Mbata IC, Xiang JZ, Anderson SA: A spatial bias for the origins of interneuron subgroups within the medial ganglionic eminence. Dev Biol 314:127-136, 2008

70. Wu C, Jermakowicz WJ, Chakravorti S, Cajigas I, Sharan $\mathrm{AD}$, Jagid JR, et al: Effects of surgical targeting in laser interstitial thermal therapy for mesial temporal lobe epilepsy: a multicenter study of 234 patients. Epilepsia 60:1171-1183, 2019

71. Yang WZ, Liu TT, Cao JW, Chen XF, Liu X, Wang M, et al: Fear erasure facilitated by immature inhibitory neuron transplantation. Neuron 92:1352-1367, 2016

72. Yin D, Valles FE, Fiandaca MS, Bringas J, Gimenez F, Berger MS, et al: Optimal region of the putamen for imageguided convection-enhanced delivery of therapeutics in human and non-human primates. Neuroimage 54 (Suppl 1):S196-S203, 2011

\section{Disclosures}

The authors report no conflict of interest concerning the materials or methods used in this study or the findings specified in this paper. 


\section{Author Contributions}

Conception and design: Southwell. Analysis and interpretation of data: Southwell. Drafting the article: both authors. Critically revising the article: both authors. Reviewed submitted version of manuscript: Southwell. Approved the final version of the manuscript on behalf of both authors: Southwell. Study supervision: Southwell.

\section{Correspondence}

Derek G. Southwell: Duke University, Durham, NC. derek. southwell@duke.edu. 